\title{
Noise characteristics of AlInN/GaN HEMTs at microwave frequencies
}

\author{
S. D. Nsele, L. Escotte, J.-G. Tartarin \\ LAAS-CNRS and University of Toulouse (UPS) \\ Toulouse, France
}

\author{
S. Piotrowicz \\ III-V Lab \\ Marcoussis, France
}

\begin{abstract}
The microwave noise parameters measured on AlInN/GaN HEMTs devices with different gate length values are presented in this paper. $0.15-\mu \mathrm{m}$ HEMTs achieve a maximum current density of $700 \mathrm{~mA} / \mathrm{mm}$ at $V_{G S}=0 \mathrm{~V}$ and a measured extrinsic transconductance of $350 \mathrm{mS} / \mathrm{mm}$. The current gain cutoff frequency and the maximum oscillation frequency are $\mathbf{4 0}$ $\mathrm{GHz}$ and $70 \mathrm{GHz}$, respectively. At 10 (20) $\mathrm{GHz}$, the device exhibits a minimum noise figure of $0.8 \mathrm{~dB}(1.8) \mathrm{dB}$ with an associated power gain of $14(8.8) \mathrm{dB}$. Below $8 \mathrm{GHz}$, the gate leakage current and a generation-recombination noise source with a very short time constant limit the noise performance.
\end{abstract}

Keywords-AIInN/GaN HEMTs; microwave noise parameters.

\section{INTRODUCTION}

Nitride-based High Electron Mobility Transistors (HEMT) can be used in robust low-noise receivers with high powerhandling properties [1]. In these technologies, AlInN/GaN HEMTs are promising devices for power applications at microwave frequencies [2]. Lattice-matched heterostructure offers a high channel charge density compared to the $\mathrm{AlGaN} / \mathrm{GaN}$ technology and a record current gain cutoff frequency $\left(f_{T}\right)$ value of $370 \mathrm{GHz}$ was reported in [3]. Furthermore, the absence of strain is an attractive feature for improving the reliability of the devices. The first noise characteristics of this type of device are reported in [4]. A minimum noise figure of $1.5 \mathrm{~dB}$ is measured at $20 \mathrm{GHz}$ with a high associated power gain of $13.5 \mathrm{~dB}$. The latter point is attractive compared to other nitride-based transistors to design multi-stage low-noise amplifiers (LNA). However, this technology suffers from a high gate leakage current and from the presence of traps and threading dislocations [5]-[7]. Trapping-detrapping processes with distributed time constants have been also reported in [8] from $100 \mathrm{kHz}$ to $1 \mathrm{GHz}$. The transconductance and $\mathrm{t}$

he output conductance exhibit frequency dispersion in this frequency range which, could be largely increased at high field due to Frenkel-Poole effect.

The noise characteristics of AlInN/GaN HEMTs grown on a $\mathrm{SiC}$ substrate are investigated at microwave frequencies. This technology is currently in development at III-V Lab, and several structures from different wafers with different gate length $\left(L_{g}\right)$ values have been characterized. The device technology is described in Section II. DC and small-signal results are reported in Section III. The noise characteristics are then presented in Section IV.

\section{DEVICE TECHNOLOGY}

Three different AlInN/GaN HEMTs devices have been studied. The dimensions and the main frequency characteristics of the different samples are reported in Table I. Fig. 1 shows the variations of the minimum noise figure $\left(N F_{\text {min }}\right)$ and associated gain $\left(G_{a}\right)$ of these devices versus the inverse of the gate length value measured at $12 \mathrm{GHz}$. As expected, the sample \#A exhibits the best noise performance $\left(N F_{\min }=1 \mathrm{~dB}\right)$ at 12 $\mathrm{GHz}$. This is mainly due to an increase of the transconductance when the gate length is reduced which also increases the operation frequency as reported in Table I. We will focus our paper on sample \#A. Fig. 2 presents the cross section of this transistor.

TABLE I. CHARACTERISTICS OF ALINN/GAN HEMTS

\begin{tabular}{|c|c|c|c|c|}
\hline & $\boldsymbol{L}_{\boldsymbol{g}}(\boldsymbol{\mu m})$ & $\boldsymbol{W}_{\boldsymbol{g}}(\boldsymbol{\mu m})$ & $\boldsymbol{f}_{\boldsymbol{T}}(\mathbf{G H z})$ & $\boldsymbol{f}_{\text {MAX }}(\mathbf{G H z})$ \\
\hline$\# \mathrm{~A}$ & 0.15 & $2 \times 75$ & 41 & 70 \\
\hline$\#^{\mathrm{a}}$ & 0.25 & $2 \times 100$ & 24 & 46 \\
\hline$\# \mathrm{C}$ & 0.70 & $2 \times 100$ & 15 & 25 \\
\hline \multicolumn{4}{|c}{}
\end{tabular}

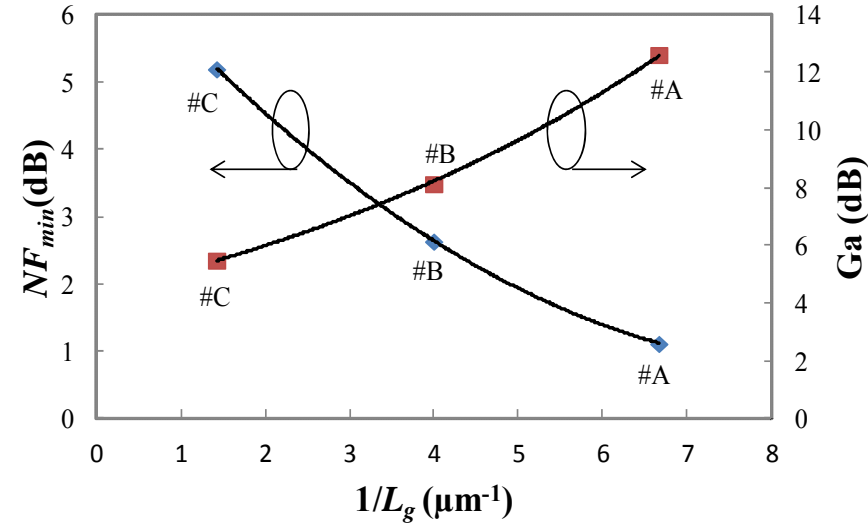

Fig. 1. Minimum noise figure and associated gain versus the inverse of gate length at $12 \mathrm{GHz}$ for different samples biased for low-noise conditions.

This work was supported by the Genghis Khan Project in the Framework of the French Research National Agency. 


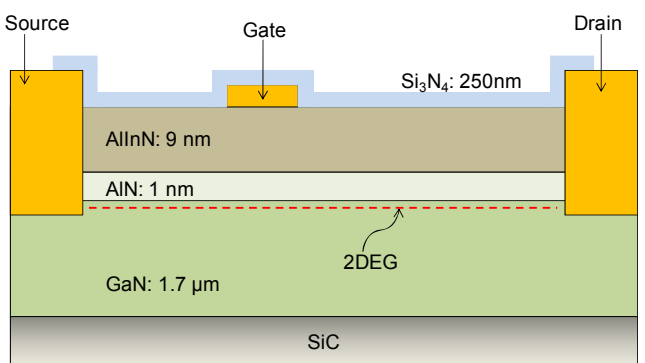

Fig. 2. Cross section of the AlInN/GaN HEMT with $0.15-\mu \mathrm{m}$-gate-length.

The layers are grown on a SiC substrate by Low Pressure Metal Organic Chemical Vapour Deposition (LP-MOCVD) using a 2-inch single wafer reactor. The heterostructures consist in a 1.7- $\mu \mathrm{m}$-thick insulating GaN buffer layer, a 1-nmthick AIN spacer layer and a 9-nm-thick undoped AlInN layer with $0.2 \%$ of Indium content.

The sheet resistance and the sheet carrier density are evaluated respectively at $330 \Omega$ and $1.52 \times 10^{13} \mathrm{~cm}^{-3}$. Ohmic contacts are formed by rapid thermal annealing of $\mathrm{Ti} / \mathrm{Al} / \mathrm{Ni} / \mathrm{Au}$ multilayer at $900{ }^{\circ} \mathrm{C}$ during $30 \mathrm{~s}$ under nitrogen ambient, and show an average resistance of $0.45 \Omega . \mathrm{mm}$. Argon ion implantation is used for device isolation. $150 \mathrm{~nm} \mathrm{Ni} / \mathrm{Pt} / \mathrm{Au} \mathrm{T}$ gates are obtained by e-gun evaporation after electron beam lithography. The devices are passivated with a 250-nm-thick $\mathrm{Si}_{3} \mathrm{~N}_{4}$ layer deposited by plasma enhanced chemical vapour deposition. A Ti/Pt/Au multilayer deposited by e-gun is used for interconnections. Multifinger device 3D interconnects are fabricated with plated gold bridge technology on photosensitive $\mathrm{BCB}$.

\section{DC AND RF CHARACTERIZATION}

DC characteristics have been realized on wafer with a precision semiconductor parameter analyzer (Agilent 4156C). Fig. 3 shows the I-V characteristics of the sample \#A. The gate-source voltage $\left(V_{G S}\right)$ varies between -4 and $0 \mathrm{~V}$ with a step of $0.5 \mathrm{~V}$, while the drain-source voltage $\left(V_{D S}\right)$ is comprised between 0 and $10 \mathrm{~V}$. The maximum drain current $\left(I_{D S}\right)$ measured at $V_{G S}=0 \mathrm{~V}\left(I_{D S S}\right)$ and $V_{D S}=10 \mathrm{~V}$ is $700 \mathrm{~mA} / \mathrm{mm}$. The peak of the extrinsic transconductance $\left(g_{m}\right)$ obtained at $\mathrm{V}_{\mathrm{GS}}$ $=-0.5 \mathrm{~V}$ and $V_{D S}=4 \mathrm{~V}$ is $=350 \mathrm{mS} / \mathrm{mm}$. The gate leakage current $\left(I_{g}\right)$ measured at $V_{G S}=-1 \mathrm{~V}$ and $V_{D S}=5 \mathrm{~V}$ is $45 \mu \mathrm{A} / \mathrm{mm}$. We obtained 1 and $10 \mu \mathrm{A} / \mathrm{mm}$ for the samples \#B and $\# \mathrm{C}$,

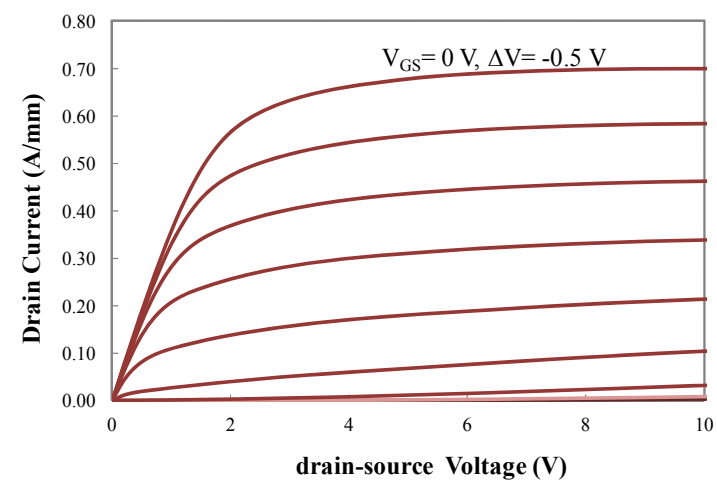

Fig. 3. Drain current $\left(I_{D S}\right)$ versus drain-source voltage $V_{D S}$ at different $V_{G S}$ values.

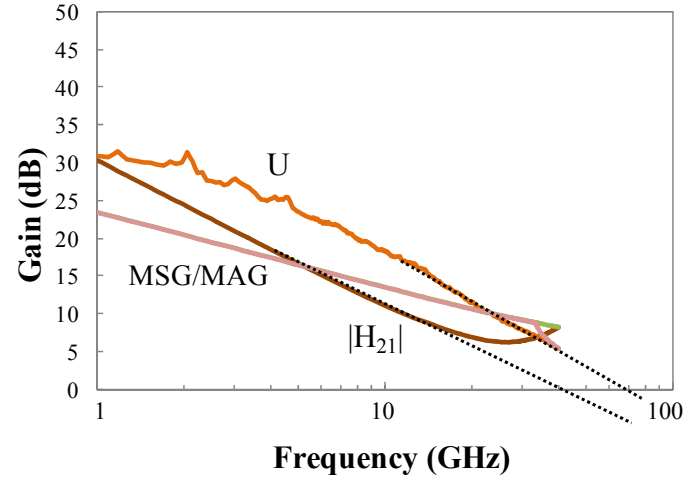

Fig. 4. Microwave performance of AlInN/GaN HEMT with $0.15-\mu \mathrm{m}-$ gate-length at $V_{D S}=5 \mathrm{~V}$ and $V_{G S}=-1 \mathrm{~V}$.

respectively.

The scattering parameters have been measured with a network analyzer (Agilent N5230C). Fig. 4 shows the microwave performances against frequency for the sample \#A measured at $V_{G S}=-1 \mathrm{~V}$ and $V_{D S}=5 \mathrm{~V}$. The extrapolation of the current gain $\left(\left|\mathrm{H}_{21}\right|\right)$ with $-20 \mathrm{~dB} /$ decade yields to a current gain cutoff frequency of $40 \mathrm{GHz}$. A maximum oscillation frequency $\left(f_{M A X}\right)$ value of $70 \mathrm{GHz}$ is also obtained by extrapolating the Mason's gain $(U)$. The maximum stable gain $(M S G)$ and the maximum available gain $(M A G)$ are also plotted in this figure.

\section{MICROWAVE NOISE CHARACTERIZATION}

The noise figure $(N F)$ of a linear two-port is given by the following relation

$$
N F=N F_{\min }+\frac{4 R_{n}}{50} \frac{\left|\Gamma_{o p t}-\Gamma_{s}\right|^{2}}{\left(1-\left|\Gamma_{s}\right|^{2}\right)\left|1+\Gamma_{o p t}\right|^{2}}
$$

where $N F_{\min }, R_{n}$ and $\Gamma_{\text {opt }}$ are the noise parameters. $\Gamma_{s}$ is the reflection coefficient presented at the input of the two-port and $\Gamma_{\text {opt }}$ corresponds to the value of $\Gamma_{s}$ obtained for minimum noise figure condition. $R_{n}$ is the equivalent noise resistance and is directly linked to the noise voltage at the input of the device. The microwave noise parameters have been measured using the multiple impedances technique between 4 and $26 \mathrm{GHz}$, with a home-made experimental test set [10] and with updated instruments. The automated test bench is controlled with a GPIB interface. Thirteen values of $\Gamma_{s}$ well distributed over the Smith chart are generated with a microwave automated tuner (MT986A) and the corresponding noise powers are measured with a noise figure analyzer (Agilent N8975A). The noise parameters are then extracted with an appropriate algorithm method. Additional information related to the experimental setup and extraction procedure can be found elsewhere [10].

Fig. 5 represents the variations of the four microwave noise parameters against frequency at $V_{D S}=5 \mathrm{~V}$ and $V_{G S}=-1 \mathrm{~V}$ for the sample \#A. The variations of $N F_{\min }$ reported in Fig.5a clearly indicate a non standard behavior. Experimental data are adjusted with the following expression 


$$
N F_{\min }=a_{0}+a_{1} f+a_{2} f^{2}+\frac{a_{3}}{f^{2}}
$$

where $a_{0}, a_{1}, a_{2}$, and $a_{3}$ are fitting parameters. The coefficient $a_{0}$ is related to the shot noise source due to the gate leakage current. Electrons injected from the gate to the channel flow into the source and the drain when a negative $V_{G S}$ is applied, inducing the gate and drain shot noise [11]. The presence of an excess noise source up to a few $\mathrm{GHz}$ (related to the coefficient $a_{3}$ in (2)) is not very usual. This has been previously reported by others in AlGaN/GaN HEMTs [12], [13]. This could be attributed to trapping-detrapping processes with very short time constants (around $1 \mathrm{~ns}$ ). We have reported in previous work [8] that these effects are present in this technology and directly impact the frequency behavior of the extrinsic transconductance and output conductance. Below 8 $\mathrm{GHz}$, the variations of $N F_{\text {min }}$ could then be attributed to a combined effect of a shot noise source, a generationrecombination (g-r) noise source, and the frequency dispersion of the transconductance and output conductance. Above $8 \mathrm{GHz}$ $N F_{\text {min }}$ increases with frequency due to diffusion noise in the channel [14]. We measured a minimum noise figure and an associated gain around $0.8 \mathrm{~dB}$ and $14 \mathrm{~dB}$ at $10 \mathrm{GHz}$, respectively. The values at $20 \mathrm{GHz}$ are $1.8 \mathrm{~dB}$ and $8.8 \mathrm{~dB}$, respectively. The noise performances are slightly lower, than those of AlGaN/GaN HEMTs featuring the same gate length value [12], [15]. However, the associated gain exhibits higher values compared to $\mathrm{AlGaN} / \mathrm{GaN}$ heterostructures, as previously observed in [4] for $0.1-\mu \mathrm{m}$ devices.

Fig. 5.b represents the variations of $R_{n}$ versus frequency. This parameter continuously decreases from 42 to $13 \Omega$ when the frequency grows. This is attributed to the presence of a g-r

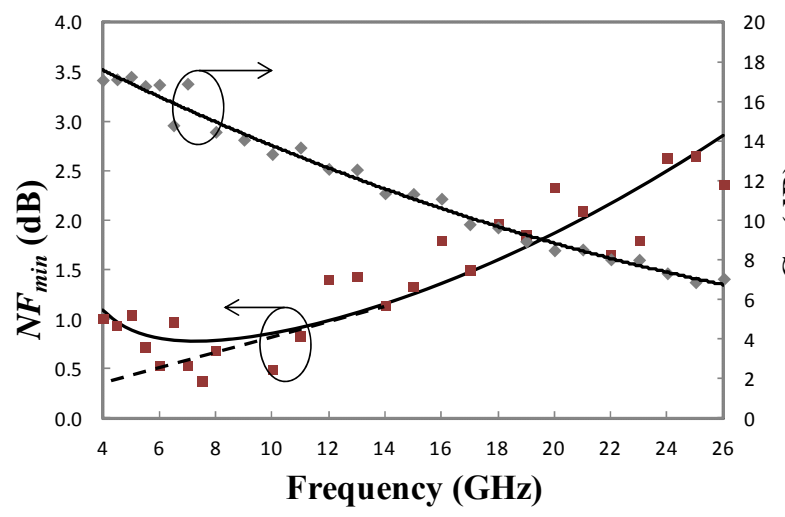

(a)

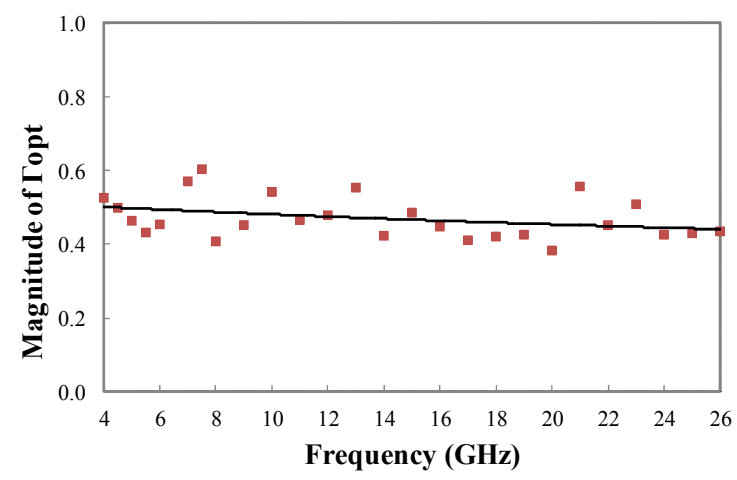

(c) noise source below $8 \mathrm{GHz}$ and to the interconnections between the test pads and the intrinsic device. The latter effect is also observed on the phase of $\Gamma_{\text {opt }}$ plotted in Fig.5d, where significant variations versus frequency are reported $\left(150^{\circ}\right.$ at 26 $\mathrm{GHz}$ ). The magnitude of $\Gamma_{\text {opt }}$ presented in Fig. 5.c slightly varies around 0.5 with frequency.

The noise parameters have been also measured at several bias points to find the optimum bias conditions for minimum noise figure operation. Fig. 6 represents the variations of $N F_{\text {min }}$ at 12 and $26 \mathrm{GHz}$ versus the ratio $I_{D S} / I_{D S S}$. The drain-source voltage is fixed at $V_{D S}=5$ and $10 \mathrm{~V}$. The minimum noise figure is achieved with a ratio of around $0.3-0.4$, corresponding to a drain current value of $200 \mathrm{~mA} / \mathrm{mm}$. This value is in agreement with previous work realized on $\mathrm{AlGaN} / \mathrm{GaN}$ devices [16], [17]. This bias point is also very close to the peak of the transconductance. Fig. 7 shows the variations of $N F_{\min }$ versus the drain-source voltage measured at a fixed $V_{G S}$ value $(-1 \mathrm{~V})$. The variations of the transconductance are also plotted on the same graph. The noise figure exhibits a minimum value at $V_{D S}$ $=5 \mathrm{~V}$, which corresponds to the peak value of the transconductance. Above $V_{D S}=5 \mathrm{~V}, N F_{\min }$ increases due to several factors: reduction of $g_{m}$, rise of $I_{D S}$, and increase of the dissipated power.

The noise performance of AlInN/GaN HEMTs could be improved by reducing the gate leakage current, which represents the limiting factor. This could be achieved by improving the Schottky contact or by using an oxide layer inserted between the AlInN barrier and the gate (MOSHEMT) [18], [19]. This has been demonstrated with $0.7-\mu \mathrm{m}$-gatelength devices. The reduction of the gate leakage current directly impacts the minimum noise figure in the "low-

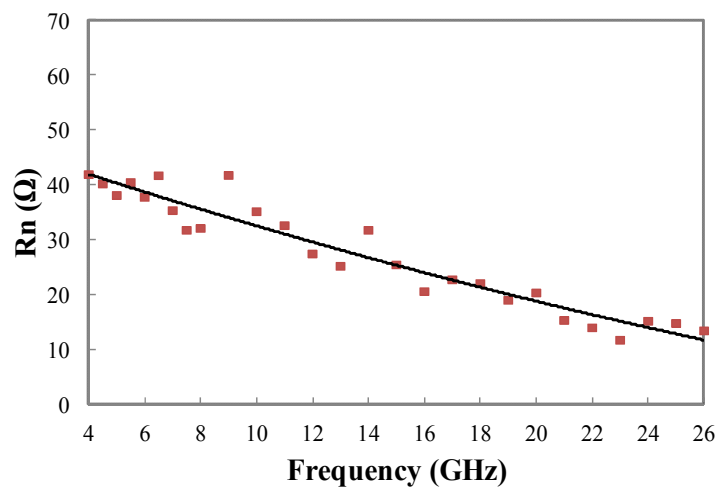

(b)

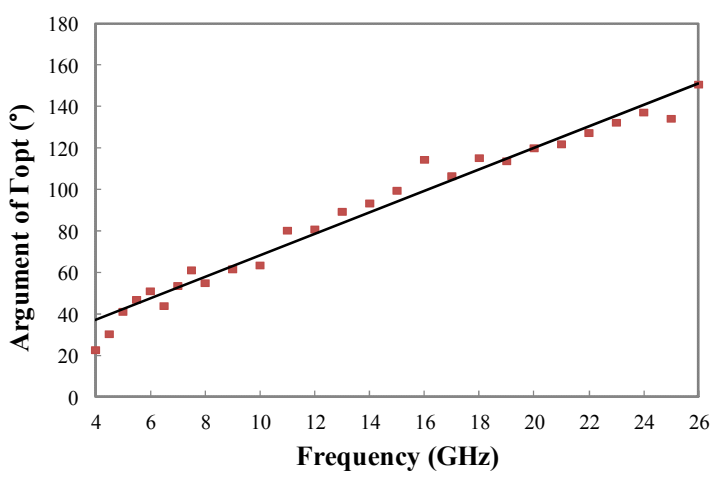

(d)

Fig. 5. Noise parameters versus frequency at $V_{D S}=5 \mathrm{~V}$ and $V_{G S}=-1 \mathrm{~V}$. (a) Minimum noise figure and associated gain. (b). Equivalent noise resistance. (c). Magnitude of the optimum reflection coefficient. (d). Argument of the optimum reflection coefficient. 


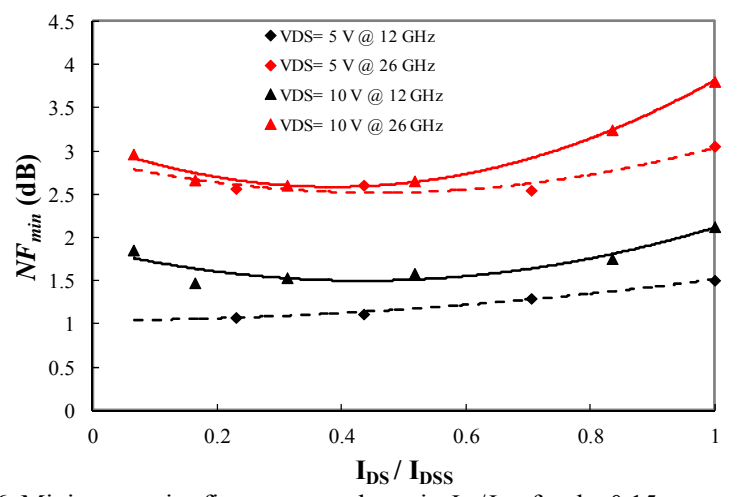

Fig.6. Minimum noise figure versus the ratio $I_{D S} / I_{D S S}$ for the $0.15-\mu \mathrm{m}$ AlInN/GaN HEMT at 12 and $26 \mathrm{GHz}$ with $V_{D S}=5 \mathrm{~V}$ and $10 \mathrm{~V}$.

frequency" range: $N F_{\min }$ is drastically reduced from $3.1 \mathrm{~dB}$ (\#C) to $1.2 \mathrm{~dB}$ (MOSHEMT) at $4 \mathrm{GHz}$.

\section{CONCLUSION}

The microwave noise parameters of different AlInN/GaN HEMTs have been presented in this paper. The noise figure in these devices is higher than the one of $\mathrm{AlGaN} / \mathrm{GaN}$ heterostructures with the same gate length value. However the measured associated power gain presents higher values which is in agreement with previous work. The main limiting factor is the gate leakage current which must be reduced to improve the overall noise performance of this technology. We have also observed the presence of an unusual excess noise source below $8 \mathrm{GHz}$ which could be attributed to trapping-detrapping processes with short time constants.

\section{REFERENCES}

[1] M. Rudolph, R. Behtash, R. Doerner, K. Hirche, J. Würfl, W. Heinrich, and G. Tränkle, "Analysis of the Survivability of GaN Low-Noise Amplifiers," IEEE Trans. Microw. Theory Tech., vol.55, no.1, pp. 3743, 2007.

[2] J. Kuzmik, "Power electronics on InAlN/(In)GaN: prospect for a record performance," IEEE Electron Device Lett., vol. 22, no. 11, pp. 510-512, Nov. 2001.

[3] Y. Yue, Z. Hu, J. Guo, B. Sensale-Rodriguez, G. Li, R. Wang, F. Faria, T. Fang, B. Song, X. Gao, S. Guo, T. Kosel, G. Snider, P. Fay, D. Jena, and H. Xing, "InAIN/AIN/GaN HEMTs with regrown ohmic contacts and $f_{T}$ of $370 \mathrm{GHz}$," IEEE Electron Device Lett., vol. 33, no. 7, pp. 988990, 2012

[4] H. F. Sun, A. R. Alt, H.-R. Benedickter, E. Feltin, J.-F. Carlin, M. Gonschorek, N. Grandjean, and C. R. Bolognesi, "Low-noise microwave performance of $0.1 \mu \mathrm{m}$ gate AlInN/GaN HEMTs on SiC," IEEE Microw. Wireless Comp. Lett., vol.20, no.8, pp. 453-455, 2010.

[5] E. Arslan, S. Bütün, and E. Ozbay, "Leakage current by Frenkel-Poole emission in $\mathrm{Ni} / \mathrm{Au}$ Schottky contacts on $\mathrm{Al}_{0.83} \mathrm{In}_{0.17} \mathrm{~N} / \mathrm{GaN}$ heterostructures," Appl. Phys. Lett., vol.94, no.14, p. 142106, 2009.

[6] W. Chikhaoui, J.-M. Bluet, M.-A. Di Forte Poisson, N. Sarazin, C. Dua, and C. Bru-Chevallier, "Current deep level transient spectroscopy analysis of AlInN/GaN high-electron mobility transistors: mechanism of gate leakage," Appl. Phys. Lett., vol.96, no.7, p. 072107, 2010.

[7] S. Pandey, D. Cavalcoli, B. Fraboni, A. Cavallini, T. Brazzini, and F. Calle, "Role of surface traps on two-dimensional electron gas density in InAlN/AlN/GaN heterostructures," Appl. Phys. Lett., vol.100, no.15, p. 152116,2012

[8] S. D. Nsele, L. Escotte, J-G. Tartarin, S. Piotrowicz, and S. L. Delage, "Broadband frequency dispersion Small signal modeling of the output conductance and transconductance in AlInN/GaN HEMTs," IEEE Trans. Electron Devices, vol. 60, no. 4, pp. 1372-1378, 2013.

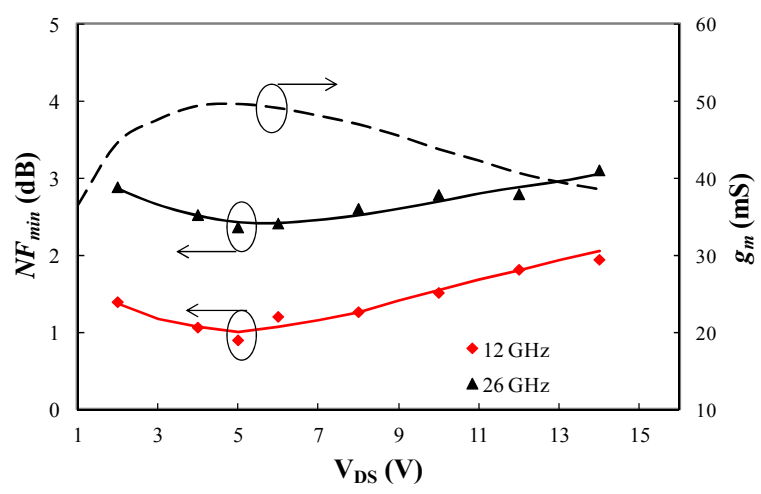

Fig. 7. Minimum noise figure and transconductance versus the drain-source voltage for the $0.15-\mu \mathrm{m}$ AlInN/GaN HEMT at 12 and $26 \mathrm{GHz}$ with $V_{G S}=-1 \mathrm{~V}$.

[9] O. Jardel, G. Callet, D. Lancereau, J.-C. Jacquet, T. Reveyrand, N. Sarazin, R. Aubry, S. Leger, E. Chartier, M. Oualli, C. Dua, S. Piotrowicz, E. Morvan, M.-A. Di Forte Poisson, and S.L. Delage, "First demonstration of AlInN/AlN/GaN HEMTs amplifiers at $\mathrm{K}$ band," in IEEE MTT-S Int. Microw. Symp., pp. 1-3, 2012.

[10]L. Escotte, R. Plana, and J. Graffeuil, "Evaluation of noise parameter extraction methods," IEEE Trans. Microw. Theory Tech., vol.41, no.3, pp. 382-387, 1993 .

[11]F. Danneville, G. Dambrine, H. Happy, P. Tadyszak, and A. Cappy, "Influence of the gate leakage current on the noise performance of MESFETs and MODFETs," Solid-State Electron., vol. 38. no. 5, pp. 1081-1087, 1995.

[12]L.P. Smorchkova, M. Wojtowicz, R. Tsai, R. Sandhu, M. Barsky, C. Namba, P.H. Liu, R. Dia, M. Truong, D. Ko, J. Wang, H. Wang, and A. Khan, "AlGaN/GaN HEMT high-power and low-noise performance at $f$ $\geq 20 \mathrm{GHz}$," in Proc. IEEE Lester Eastman Conf. on High Performance Devices, pp. 422-427, 2002.

[13]S. Lee, K. J. Webb, V. Tilak, and L. F. Eastman, "Intrinsic noise equivalent-circuit parameters for AlGaN/GaN HEMTs," IEEE Trans. Microw. Theory Tech., vol.51, no.5, pp. 1567-1576, 2003.

[14]R. A. Pucel, D. J. Masse, and C. F. Krumm, "Noise performance of gallium arsenide field effect transistors," IEEE Jour. Solid-State Circuits, vol. 11 , no. 2 , pp. 243-255, 1976.

[15]J.S. Moon, M. Micovic, A. Kurdoghlian, P. Janke, P. Hashimoto, W.-S. Wong, L. McCray, and C. Nguyen, "Microwave noise performance of AlGaN/GaN HEMTs with small DC power dissipation," IEEE Electron Device Lett., vol. 23, no. 11, pp. 637-639, 2002.

[16]J.-W. Lee, A. Kuliev, V. Kumar, R. Schwindt, and I. Adesida "Microwave noise characteristics of $\mathrm{AlGaN} / \mathrm{GaN}$ HEMTs on $\mathrm{SiC}$ substrates for broad-band low noise amplifier," IEEE Microw. Wireless Comp. Lett., vol. 14, no. 6, pp. 259-261, 2004.

[17]V. Hoel, N. Defrance, Y. Douvry, J. C. De Jaeger, N. Vellas, C. Gaquiere, M. A. di Forte-Poisson, J. Thorpe, and R. Langer, "Low microwave noise of AlGaN/GaN HEMTs fabricated on SiCopSiC substrates," Electron. Lett., vol. 46, no. 1, pp. 84-85, 2010.

[18]M. Alomari, F. Medjdoub, J.-F. Carlin, E. Feltin, N. Grandjean, A Chuvilin, U. Kaiser, C. Gaquière, and E. Kohn, "InAlN/GaN MOSHEMT with self-aligned thermally generated oxide recess," IEEE Trans. Electron Devices, vol. 30, no. 11, pp. 1131-1133, 2009.

[19]T.-Y. Wu, S.-K. Lin, P.-W. Sze, J.-J. L. Huang, W.-C. Chien, C.-C. Hu, M.-J. Tsai, and Y.-H. H. Wang, "AlGaN/GaN MOSHEMTs with liquidphase-deposited $\mathrm{TiO}_{2}$ as gate dielectric," IEEE Trans. Electron Devices, vol. 56, no. 12, pp. 2911-2916, 2009. 